\title{
Steel Plastic Geogrid Performance Testing and its Application in the Reduction of Spring Back of Shotcrete
}

\author{
Wang Qingbiao ${ }^{1,2,3, *}$, Zhang Cong ${ }^{2}$, LÜ Rongshan ${ }^{2}$, Wen Xiaokang ${ }^{2}, \mathrm{Xu} \mathrm{Lei}^{2}$, Wang Tiantian ${ }^{2}$ \\ and Zhang Junxian ${ }^{2}$
}

${ }^{I}$ Department of Resource and Civil Engineering, Shandong University of Science and Technology, Tai'an Shandong 271019, P.R. China; ${ }^{2}$ College of Civil Engineering and Architecture, Shandong University of Science and Technology, Qingdao Shandong 266590, P.R. China; ${ }^{3}$ Shandong Hualian Mining Co., Ltd., Yiyuan Shandong 256119, P.R. China

\begin{abstract}
In order to solve the problems of high springback of sprayed concrete and high dust concentration in the boltnetting support of underground engineering, research the mechanical properties of steel plastic geogrid and analyze the application of steel plastic geogrid replacing the metal net in the reduction of concrete through theoretical study, laboratory test, field test and contrast analysis, thus got the conclusion that: (1) Through the analysis of influence factors of the springback of surrounding rock supporting sprayed concrete, classification is carried on with the sampling survey method. The interaction between the metal net and concrete is the main factor to influence the springback of the concrete. (2) Study the performance differences of the steel plastic geogrid and the metal net. With the advantages of tensile strength, strong durability and injection connection, steel plastic geogrid has stronger applicability, safety and stability in adjusting the stress of the surrounding rock of the roadway and coordinating its deformation. (3)Through the tensile test and the deflection test, study the relationship between the tensile strength and external load under different aperture, thus establish the relation curve between the maximum deflection and load. (4) Through the roadway engineering construction and the analysis of the data of the field test, steel plastic geogrid can greatly reduce the springback of sprayed concrete which can guide the design and construction of underground bolt-netting support engineering.
\end{abstract}

Keywords: Steel plastic geogrid, mechanical properties, tensile test, deflection tests, springback.

\section{INTRODUCTION}

Spraying concrete plays an important role in the construction of foundation engineering, which is an important support for rock surroundings. However, the high springback rate and value not only cause the waste of raw material, the increase of the engineering cost, the direct extension of the work time of spraying concrete and the impact on the construction progress, but also make the dust content too high in the construction site which is a serious threat to the health of the construction personnel $[1,2]$. Therefore, it is extremely necessary to take practical and effective measures to reduce the springback of the sprayed concrete, shorten the construction period and ensure the life safety of the construction personnel.

David Stackelberg, Boris Wilge, Shimo Boiko and Banthia N,Majdzadeh [3, 4] studied the strength improvement and stability of sprayed concrete. According to the test result of fiber concrete in direct shear and bending shear, put forward the key technology to improve the mechanical performance of concrete mestic. Domestic research;Xu Yonghong and Li Kaiqi [5] studied the strength of the sprayed concrete in the coal mine tunnel, developed special enhancer and conducted cement paste test and compressive strength

*Address correspondence to this author at the Department of Resource and Civil Engineering, Shandong University of Science and Technology, No 223, Daizong Street, Taishan District, Tai'an Shandong 271019, P.R. China; Tel: +86 18805381111; E-mail: 1349725165@qq.com. test which greatly improved the strength of the concrete.Qin Lian and Zhang Xiong [6] developed new alkali free liquid accelerator with the organic and inorganic chemistry theory,optimized the accelerator by polymer material to reduce the springback of the concrete.Zeng Xiantao and Ren Zhenhua [7] introduced a concept of magnetized water.Through the different intensity of magnetized water mixed with sprayed concrete, the sprayed concrete intensity is greatly improved. Pang Jianyong and Lv Pei [8] use largespan space shell mechanics principle,further studied the polypropylene net shell anchor spray support technology,which is effective in the soft rock tunnel support.Gao Zhihua [9] and Yao Chuanqin [10] studied the accelerator in the process of spraying concrete and various methods and techniques to reduce the springback in the support process and achieved fruitful results.

However, in the current study, there are still many deficiencies. Some research focus on the development of the sprayed concrete accelerator to improve its early strength, but because of the difference in the early and late strength, water cement ratio and the configuration of the accelerator, the springback is largely unable to be effectively reduced. Some research focus on the using of wet sprayed concrete construction, and achieved good results in the support technology, but because of the differences in the construction environment and personnel technical level, it's hard to solve the problem of concrete springback. Some research focus on the introduction of new engineering materials, such as poly- 
ethylene, polypropylene materials, but the feasible study, the mechanical properties and the safety and stability of the new materials lack of further experimental verification.

Therefore, having an in-depth research of the method to reduce the springback of the sprayed concrete in the supporting process, analyzing the reason and influencing factors of the springback, actively introducing new materials and technology and having laboratory test and field test of the concrete performance of new materials has important engineering reference and guidance in solving the loss of concrete springback and dust problems, and improving the economic and social benefit of the project.

\section{THE INFLUENCING FACTORS OF THE SPRAYED CONCRETE SPRINGBACK}

The technology of spraying concrete plays an important role not only in the tunnel engineering support, but also in the underground engineering support such as underground cavern and tunnel. However, in the process of surrounding rock supporting construction, the high springback value and dust concentration, on the one hand, makes the low visibility of working face in the process of construction, cause great deviation in the concrete proportion, which greatly influence the construction personnel on the quality control, thus cause the supporting failure and increase the costs; on the other hand, has a serious impact on the health of the personnel which is potentially devastating [11]. Therefore, it is extremely necessary to launch the research on reducing the springback of the sprayed concrete. Through the field survey of Wo-hushan mine and Xia-gou mine of Hualian Mining, combined with the site construction of the tunnel surrounding rock support, the detection results are summarized in Table 1.

Table 1. The summary sheet of test times.

\begin{tabular}{|c|c|c|c|}
\hline $\begin{array}{l}\text { Influencing } \\
\text { Factors }\end{array}$ & $\begin{array}{l}\text { The metal net } \\
\text { and concrete } \\
\text { action }\end{array}$ & \multicolumn{2}{|c|}{$\begin{array}{l}\text { The control difference of wind } \\
\text { and water pressure and jet dis- } \\
\text { tance }\end{array}$} \\
\hline $\begin{array}{c}\text { Test } \\
\text { times }(100)\end{array}$ & & \multicolumn{2}{|c|}{25} \\
\hline $\begin{array}{l}\text { Influencing } \\
\text { Factors }\end{array}$ & $\begin{array}{c}\text { Unreasonable } \\
\text { concrete mix ratio }\end{array}$ & $\begin{array}{l}\text { Nonstandard } \\
\text { additive addi- } \\
\quad \text { tion }\end{array}$ & $\begin{array}{l}\text { Unreason- } \\
\text { able jet } \\
\text { order }\end{array}$ \\
\hline $\begin{array}{c}\text { Test } \\
\text { times }(100)\end{array}$ & 14 & 11 & 7 \\
\hline
\end{tabular}

The table indicates that the interaction between metal net and concrete has a great influence on the loss of the sprayed concrete springback. In the 100 sampling, the influence degree reached $43 \%$. Secondly, the poor control of the wind and water pressure and jet distance and the unreasonable concrete mix ratio are also important aspects causing springback problems, which influence degree reached $39 \%$. This is mainly because the nature of the metal net and concrete ma- terial is different. The force between the two is completed mainly through the adsorptive cementation stress between metal net and concrete, the friction on contact surface, the mechanical bite force resulted by the uneven surface of the steel and the concrete, and the anchorage force generated by the hooking and bending of the steel end. However, the metal net used in the tunnel support is the straight segment smooth steel formed through weaving effect, thus the friction and mechanical bite force with the concrete is very small; rely mainly on the force between the chemical bonding force and the grid. Therefore, the sprayed concrete in part through the acting of the metal mesh grid and the surrounding rock, partly because of the collision of concrete and metal mesh grid or its slump before the concrete is not condensed caused the increase of the amount of springback.

On the other hand, in the tunnel construction process, because the wind and water pressure of the jet concrete is larger, there's a large part of concrete aggregate greatly impacted with the metal net, thus the springback generated. In the process of injection, the working surface is narrow and the requirement of the jet distance cannot be satisfied in most cases which lead to the high springback of the concrete. In addition, the unreasonable concrete mix ratio, some additives such as quick-setting agent and unreasonable jet order also result in the increase of concrete springback. So the key to solve the high springback of sprayed concrete is to solve the bolt-netting support materials.

\section{THE CONTRAST RESEARCH OF STEEL PLASTIC GEOGRID AND METAL NET IN REDUCING THE SPRINGBACK}

\subsection{The Introduction of Steel Plastic Geogrid Materials}

Because the effect of the traditional metal net support is not ideal, in recent years, new bolt-netting support materials play a more and more important role in the surrounding rock supporting engineering with our constant exploration in new materials. The steel plastic geogrid, as a new type of geotechnical material, showed a good application effect compared with traditional metal net support, largely solved the problems caused by underground bolt-netting support materials. Fig. (1) is the physical map of steel plastic geogrid and metal net.

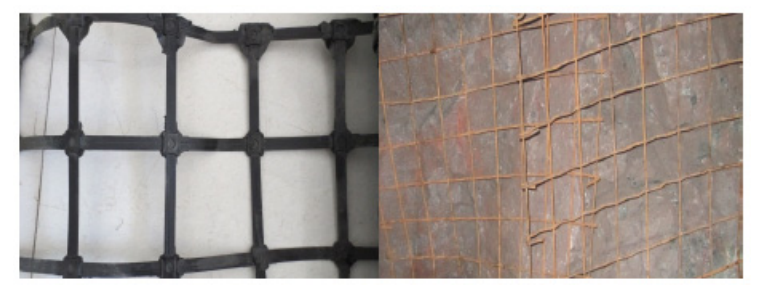

Fig. (1). The physical map of steel plastic geogrid and metal net.

\subsection{Comparison of Advantages and Disadvantages of Steel Plastic Geogrid and Metal Net}

Through the analysis of the advantages and disadvantages of steel plastic geogrid and metal net, choose the $\Phi 0.7 * 12$ steel plastic geogrid and $\Phi 6$ metal net to have a comparative study, and the advantages and disadvantages are shown in Table. 2. 
Table 2. Comparison of advantages and disadvantages of steel plastic geogrid and metal net.

\begin{tabular}{|c|c|c|}
\hline Class scope & $\begin{array}{l}\text { Steel plastic geogrid } \\
(\text { per meter } \Phi 0.7 * 12)\end{array}$ & Metal net (Ф6) \\
\hline Corrosion resistance & Strong corrosion resistance with the outer layer of superpolymer & $\begin{array}{l}\text { Certain corrosion resistance combined } \\
\text { with the concrete }\end{array}$ \\
\hline Construction time & The average time for laying net $10 \mathrm{~min} / \mathrm{m}^{2}$ & $\begin{array}{l}\text { The average time for laying net } \\
\qquad 25 \mathrm{~min} / \mathrm{m}^{2}\end{array}$ \\
\hline Entirety & The area is generally $(1.5 \sim 6) \mathrm{m} \times(50 \sim 100) \mathrm{m}$, with good integrity & The area is generally $1 \mathrm{~m}^{2}$ \\
\hline Connection mode & $\begin{array}{l}\text { Injection connection, the shear strength of the node is over } 1.5 \mathrm{MPa} \text {, the } \\
\text { limit peeling force of the nodes is } \geq 300 \mathrm{~N}\end{array}$ & Braiding forms with poor sterngth \\
\hline quality $/ \mathrm{m}^{2}$ & $\begin{array}{l}\text { The per square meter weight is only about } 1 \mathrm{~kg} \text {, and can be transported in } \\
\text { rolls }\end{array}$ & $\begin{array}{l}\text { The per square meter weight is about } \\
\qquad 5 \mathrm{~kg}\end{array}$ \\
\hline
\end{tabular}

In the supporting process, the steel plastic geogrid can be laid without connection, save networking time and the moving speed is very fast which can avoid the problem of laying net slowly in certain parts and poor integrity of the metal net. Save at least half the time, safe and reliable, with strong construction adaptability.

In summary, although metal net can disperse surrounding rock stress and ensure its overall stability in the tunnel surrounding rock supporting, in the area of great surrounding rock pressure and easily broken layer, especially the steel ultimate tensile strength and the tear strength of the node can hardly guarantee the overall stability of the surrounding rock in the above stress condition. Steel plastic geogrid has the advantages of high tensile strength, low cost, strong durability, corrosion resistance, flame retardant and anti-static and simple overlapping. As a new geotechnical material, it has strong applicability in coordinating the deformation of surrounding rock compared with the traditional metal net support. The injection connection in the node of steel plastic geogrid guarantees its entire supporting stability.

\section{THE MECHANICAL PROPERTY TEST}

In the study of reducing springback of steel plastic geogrid in the underground engineering, the interaction with the concrete is the key to the research. The mechanical properties will be influenced differently in different surrounding rock conditions, thus in the course of the spraying concrete, the springback produced is not the same. Therefore, the experimental research on the mechanical properties of steel plastic geogrid and metal net is conducted to analyze the effect on the springback of sprayed concrete. Among them, the tensile strength and deflection are two important performance indexes.

\subsection{Tensile Test}

\subsubsection{The Design and Plan of the Test}

The test is conducted in Tai' an Bureau of Quality and Technical Supervision and Tai'an Construction Quality Supervision Station. The test instruments are hydraulic univer- sal tensile machine and DR028J universal material testing machine, as shown in Fig. (2) and Fig. (3).

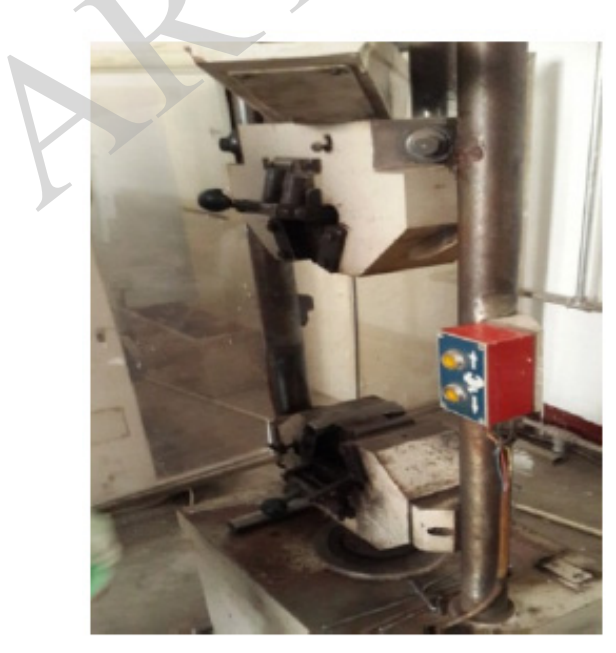

Fig. (2). Hydraulic universal tensile machine.

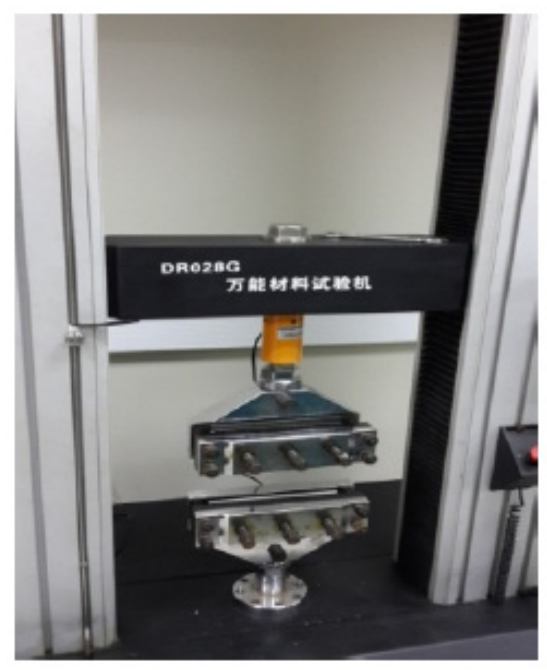

Fig. (3). DR028J universal material testing machine. 
Because the tensile strength of the steel plastic grid net and metal met is big, only a single steel plastic geogrid is chosen to have the comparative test with the steel bar. Three different specifications of steel plastic geogrid of $\Phi 0.7 \times 8, \Phi$ $0.7 \times 12, \Phi 0.7 \times 18$ is used in the tensile strength test and the steel bar for test is $\Phi 4, \Phi 6, \Phi 8$. Hydraulic universal tensile machine is the $50 \mathrm{KN}$ tensile test instrument, using highspeed DSP platform and adaptive PID algorithm all digital force, deformation and displacement control system. During the test, the steel plastic geogrid and a single steel bar is fixed in the two ends of the tensile machine by the anchorage to be stretched. The tensile machine and test machine are automatically controlled by the computer, dynamically display the loading value, displacement value, deformation value, test speed and test curve.

\subsubsection{Test Results}

\section{(1) Tensile test of steel plastic geogrid}

According to the testing process of hydraulic universal tensile machine and DR028J universal material testing machine, the tensile test curve is shown in Fig. (4) and the tensile failure test is shown in Fig. (5).

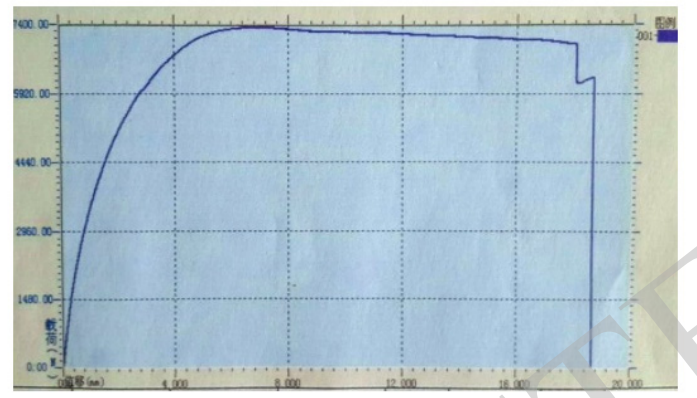

(a) $\Phi 0.7 \times 8$

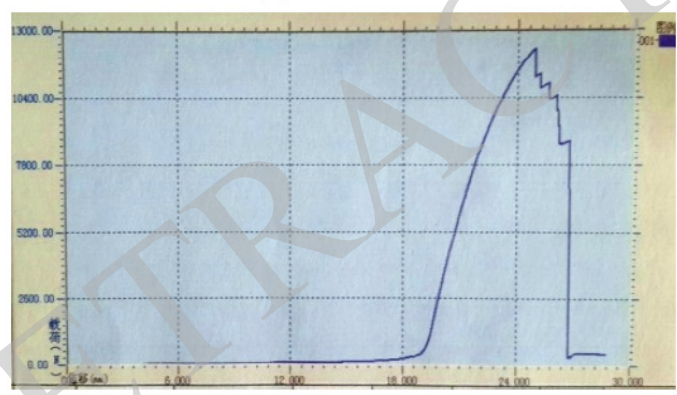

(b) $\Phi 0.7 \times 12$

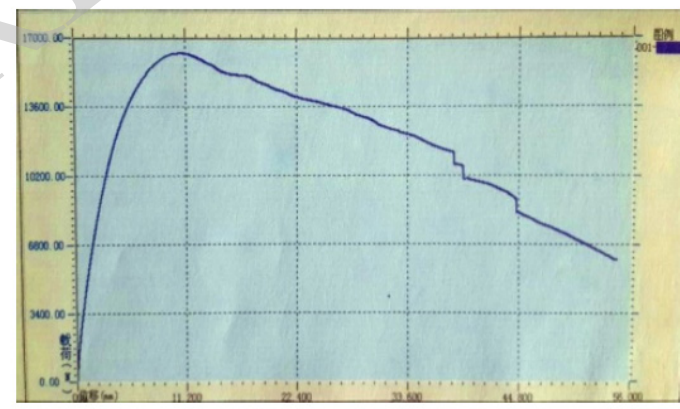

(c) $\Phi 0.7 \times 18$

Fig. (4). The Tensile Test Curve of Steel Plastic Geogrid of $\Phi$ $0.7 \times 8, \Phi 0.7 \times 12, \Phi 0.7 \times 18$.
As is shown in Fig. (4) (a), the tensile curve of $\Phi 0.7 \times 8$ steel plastic geogrid, with the continuous increase of applied load at both ends, the displacement increases and is in linear relationship with the increase of the load. When reaches $7.4 \mathrm{KN}$, the load-displacement curve gradually slow, and with the increase of the displacement, the load decreases gradually. When the displacement reaches $18.6 \mathrm{~mm}$, fracture happens. At this time, due to the internal steel wire, the ladder line form appears. As is shown in Fig. (4) (b) the tensile curve of $\Phi 0.7 \times 12$ steel plastic geogrid, with the gradually increasing load, the tensile curve has the upward trend at the beginning and the displacement increases, too. When the load reaches $12.292 \mathrm{KN}$, because the test fixture slips, the grid rib belt slides, and the inner steel wire bear the main load. When reaches the steel yield strength, the steel wire in the fixture begin to break one by one, resulting in the sudden drop in the tensile curve, rapid decrease in the strength and obvious decline curve in the ladder line, but the steel plastic geogrid has not reached its ultimate tensile strength at this time. As is shown in Fig. (4)(c) the tensile curve of $\Phi 0.7 \times 18$ steel plastic geogrid, tensile curve zooms at the beginning.

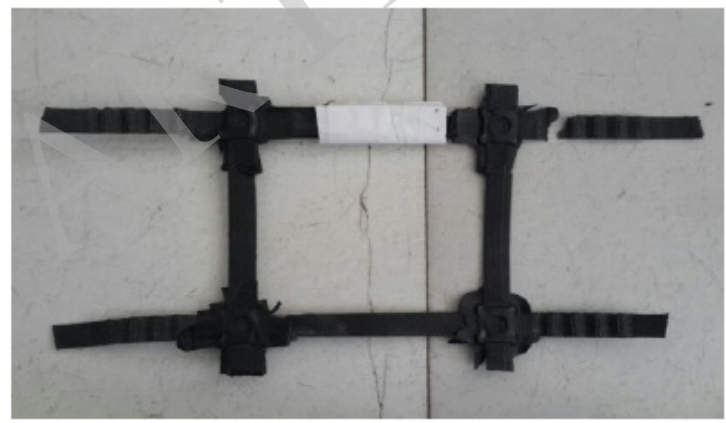

(a) $\Phi 0.7 \times 8$

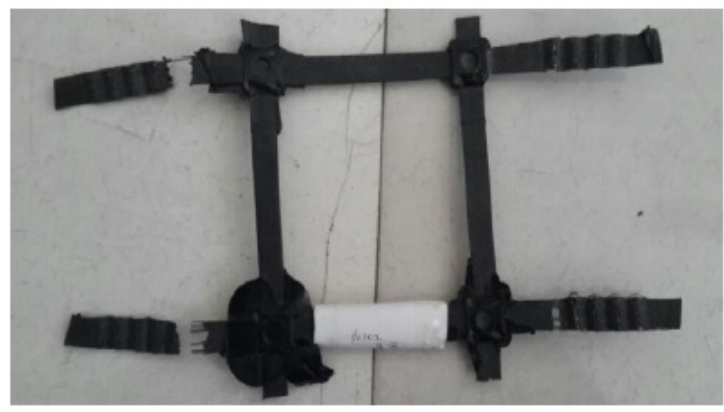

(b) $\Phi 0.7 \times 12$

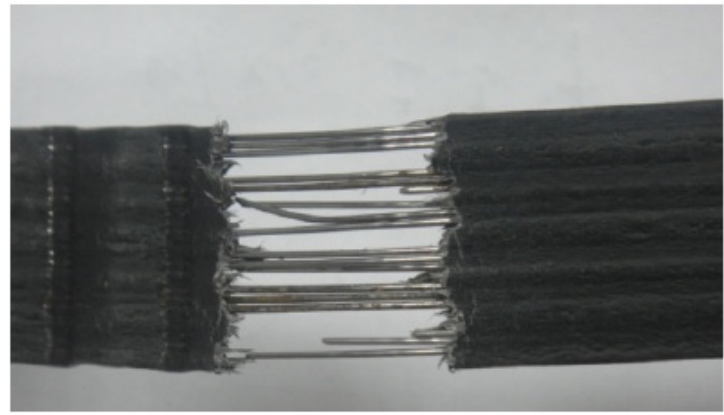

(c) $\Phi 0.7 \times 18$

Fig. (5). The Tensile Failure Diagram of Steel Plastic Geogrid of $\Phi$ $0.7 \times 8 、 \Phi 0.7 \times 12 、 \Phi 0.7 \times 18$. 
From the above test results, the maximum single strength of the $\Phi 0.7 \times 8$ steel plastic geogrid is $7.4 \mathrm{KN}$ and the tensile strength per meter is $59.2 \mathrm{KN}$ by calculation. The maximum single strength of the $\Phi 0.7 \times 12$ steel plastic geogrid is $16 \mathrm{KN}$ and the tensile strength per meter is $128 \mathrm{KN}$ by calculation. The maximum single strength of the $\Phi 0.7 \times 18$ steel plastic geogrid is $17 \mathrm{KN}$ and the tensile strength per meter is $13 \mathrm{KN}$ by calculation. The grid used in the test is $125 \mathrm{~mm} \times 125 \mathrm{~mm}$. If the grid narrowed, the strength will be greater.

\section{(2) The tensile test of metal net}

The diameter of the metal net steel bar used in the test is $\Phi 4$ and $\Phi 6$, the length and width of the net is $1000 \mathrm{~mm} \times 1000 \mathrm{~mm}$ and the hole is $125 \mathrm{~mm} \times 125 \mathrm{~mm}$. The test demonstrates that the ultimate tensile strength of the $\Phi 6$ metal net is only $16 \mathrm{KN}$ which is lower than the steel plastic geogrid of the same specification. Metal net damage occurred at $77 \mathrm{KN}$, leading to the loss of surrounding rock supporting effect.

\subsection{Deflection Test}

The steel geogrid in the deflection test is $\Phi 0.7 \times 12$, the length and width is $1000 \mathrm{~mm} \times 1000 \mathrm{~mm}$ and the inside diameter of the hole is $125 \mathrm{~mm} \times 125 \mathrm{~mm}$. The diameter of the welding metal net steel is $\Phi 6$, the length and width of the net is $1000 \mathrm{~mm} \times 1000 \mathrm{~mm}$ and the hole is $125 \mathrm{~mm} \times 125 \mathrm{~mm}$. The deflection of the center and the midpoint of the edges are tested. The test scheme is shown in Fig. (6) and the result is shown in Fig. (7).

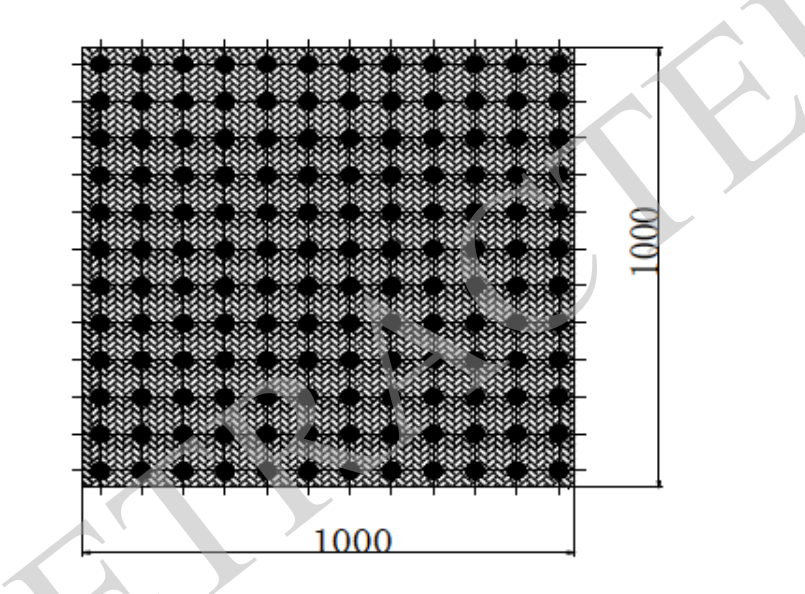

Fig. (6). Deflection Test Scheme.

As is shown in Fig. (7), with the load continuously applied, the deflection of steel plastic geogrid increases gradually and they're in a proportional relation. The steel in the metal net has good ductility when the ultimate load bearing is $120 \mathrm{KN}$ and the deflection value reaches $350 \mathrm{~mm}$. But with the increase of applied loads, when the load bearing is $77 \mathrm{KN}$, and the maximum deflection reaches $220 \mathrm{~mm}$, there's a big gap with steel plastic geogrid. Therefore, the deformationa ability of steel plastic geogrid is far greater than that of the metal net.

From the above study, we can see that, in the mechanical properties, tensile strength and deflection capability, steel plastic geogrid is superior to metal net in reducing the springback of sprayed concrete.
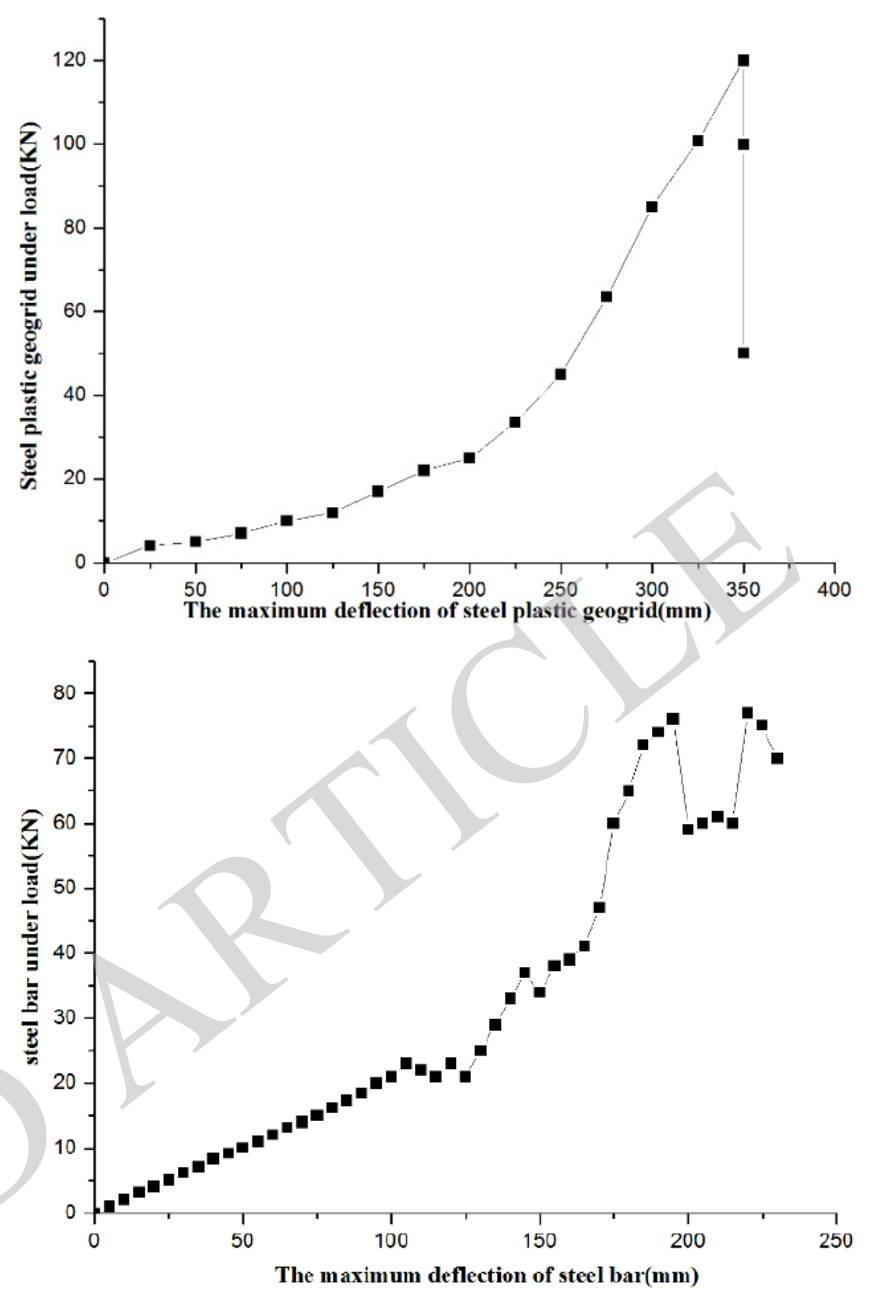

Fig. (7). The Relationship of Maximum Deflection and The Applied Load in Steel Plastic Geogrid and Metal Net.

\section{THE APPLICATION OF STEEL PLASTIC GEOG- RID IN TUNNEL ENGINEERING}

\subsection{Overview of The Project}

The lithology of Shandong Hualian mining Xia-gou ore is mainly hornblende plagioclase gneiss, biotite plagioclase gneiss and iron hornblende schist. The crack is not developed, and the fracture zone is filled with fault breccias, cataclastic limestone, shale, pegmatitic granite and gneiss. There are many surrounding rock supporting parts in the tunnel, and mainly uses bolt-netting support. The high springback of sprayed concrete and high dust concentration is a serious threat to the life safety of the constructors.

\subsection{Field Contrast Test}

According to the tunnel construction design and the requirements of the test site, select $30 \mathrm{~m}$ and $10 \mathrm{~m}$ as a group in the $20 \mathrm{~m}$ of the vein roadway and $40 \mathrm{~m}$ in the +10 horizontal transfer layer contact lane of the 0 meter horizontal line 7 in the tunnel, and there are three test groups. The on-site comparison test is conducted with steel plastic geogrid and metal net as bolt-netting support materials, and the water cement ratio is 1:2. After spraying concrete, collect the springback data of three different test points with random sampling 
Table 3. Steel Plastic Geogrid/ Metal Net Spray Springback Statistics (unit: $\mathbf{m}^{2}$ ).

\begin{tabular}{|c|c|c|c|}
\hline tunnel position $\quad$ group & Group 1 (the left side) & Group 2 (in the middle) & Group 3 (the right side) \\
\hline The vein roadway in the 0 meter horizontal line 7 & $2.4 / 3.1$ & $1.9 / 2.5$ & $2.5 / 3.5$ \\
\hline+10 horizontal transfer layer contact lane & $2.5 / 3.9$ & $2.0 / 2.6$ & $2.7 / 3.8$ \\
\hline
\end{tabular}

methods, take the average value as the springback value, and analyze the collected data as is shown in Table 3. Fig. (8) and Fig. (9) are the test of sprayed concrete of metal net and steel plastic geogrid.

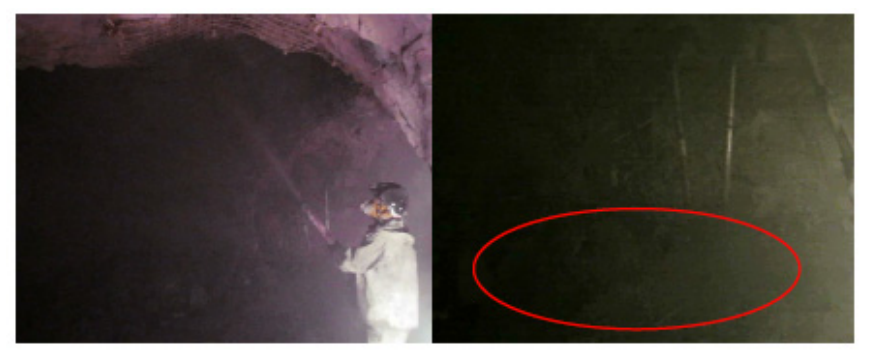

Fig. (8). Field test of metal net spraying concrete.

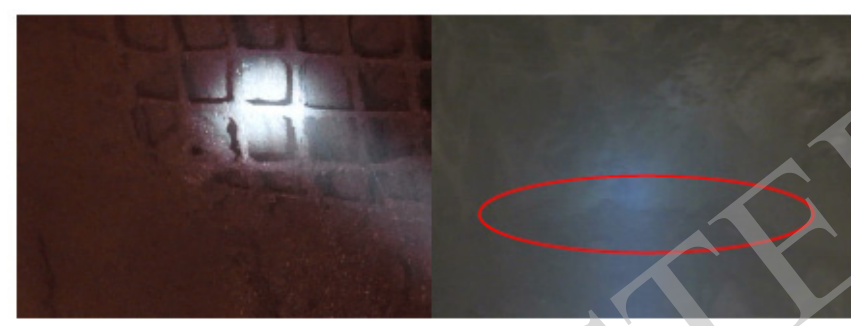

Fig. (9). Field test of steel plastic geogrid spraying concrete.

From the field tests, we can see that spraying concrete in the test period, as the bolt-netting support material, steel plastic geogrid produced less springback than the metal net. In the vein roadway of the 0 meter horizontal line 7 test section, the springback of the middle group(steel plastic geog$\mathrm{rid} /$ metal net is $1.9 / 2.5$ ) is obviously less than that of the side groups (the left side: steel plastic geogrid/ metal net is 2.4/3.1; the right side: steel plastic geogrid/ metal net is $2.5 / 3.5)$. The main reason is, on the one hand, the concrete is restricted by the terrain and the tunnel position. In the vein roadway of the 0 meter horizontal line 7 , in order to ensure the corner has enough strength, the spraying time on both ends of the test section is longer and thicker, thus the springback in the spraying process increased. On the other hand, the middle test section located in the connecting position of both sides. In the process of spraying concrete in the tunnel surrounding rock, the spray of the transition section is greatly influenced by both sides. Because of the spray sequence, techniques and the technical level of the conductors, the springback is larger and the dust concentration is higher. In the +10 horizontal transfer layer contact lane test section, the springback is higher than the former section mainly because there're many corners. The concrete springback peaked at $3.9 \mathrm{~m}^{2}$ under the action of metal net which is one third more than that of steel plastic geogrid. Even in the middle section, steel plastic geogrid also showed considerable advantage in reducing the springback of sprayed concrete.

As is shown in the above tables and figures, based on field test, steel plastic geogrid can greatly reduce the springback of sprayed concrete compared with metal net. But because of the surrounding rock of the tunnel, spraying techniques and the technical level of the conductors, the problem of springback has not been solved fundamentally. Therefore, steel plastic geogrid is feasible in the tunnel support. But the supporting construction process is still need to be optimized in order to reduce springback and guarantee and improve the safety and quality of the construction.

\section{CONCLUSION}

(1) Through the study of influence factors of sprayed concrete springback in the underground engineering boltnetting support, combined with the site operation, classify the influence factors with the sampling survey method. The interaction between the metal net and the concrete is the main factor to influence the springback. The wing and water pressure, jet distance and the technical level of the conductors greatly influence the springback.

(2) Study the performance difference between steel plastic geogrid and metal net, and carry on the contrast. Steel plastic geogrid has the advantages of great tensile strength, strong durability, strong corrosion resistance, low construction cost and convenient overlapping. In adjusting surrounding rock stress and coordinating rock deformation, it has better applicability and safety than the metal net support. The injection connection of the node ensures the stability of the overall support of steel plastic geogrid.

(3) Through the laboratory test of mechanical properties, analyze the mechanical effect of the springback of both steel plastic geogrid and metal net. Based on the tensile test, study the relation between steel plastic geogrid and the applied load under different bore diameters, establish the curve of maximum deflection and load, verify the feasibility of steel plastic geogrid replacing metal net in bolt-netting support from mechanical property aspects.

(4) By combining with the actual tunnel engineering construction, the field test is carried on in the application of reducing springback of sprayed concrete. According to the test results, we can conclude that steel plastic geogrid can reduce the springback to a large extent. However, due to the constraints of the surrounding rock conditions in the tunnel, injection technology and the technique level of the conductors, the construction technology of 
spraying concrete in underground engineering still needs further optimization and improvement.

\section{CONFLICT OF INTEREST}

The authors confirm that this article content has no conflict of interest.

\section{ACKNOWLEDGEMENTS}

This work was financially supported by:

(1) National Natural Science Foundation of China (NSFC) (41372289);

(2) The Open Research Fund of State Key Laboratory of Geomechanics and Geotechnical Engineering, Institute of Rock and Soil Mechanics, Chinese Academy of Sciences (2012003);

(3) A Project of Shandong Province Higher Educational Science and Technology Program (12LH03);

(4) China's Post-doctoral Science Fund (2012M521365).

\section{REFERENCES}

[1] Zeng Xiantao, Ren Zhenhua, Wang Xingguo. Experimental investigations on reducing the dust density and the springback rate of shotcrete by using magnetized water.Journal of China Coal Society, vol. 39, pp.705-712, 2014.

[2] HUANG Tian-yong, WANG Dong-min, LIU Ze. Selection and Performance Research on Wet Spraying Materials in Coal Mine.
BULLETIN OF THE CHINESE CERAMIC SOCIETY, vol. 33, pp. 470-475, 2014.

[3] David Stackelberg, Boris Wilge, Shimo Boiko. Principles of Monitoring Hardening and Strengthening of Shotcrete. Journal of the Chinese Ceramic Society, vol. 42, pp. 568-573, 2014.

[4] Banthia N, Majdzadeh F, Wu J, et al. Fiber synergy in Hybrid Fiber Reinforced Concrete (HyFRC) in flexure and direct shear. Cement and Concrete Composites, vol. 48, pp. 91-97, 2014

[5] XU Yong-hong, LI Kai-q,i LI Jin-hai. Test and Research on High Strength and High Performance Shotcrete. Coal Science and Technology, vol. 37, pp. 32-35, 2009.

[6] QIN Lian, ZHANG Xiong, ZHANG Yong-juan. Develop-ment and Optim izing-m ixing of New-type Non-alkaline Liquid Accelerator of Shotcrete. Journal of SouthwestUniversity of Science and Technology, vol. 22, pp. 30-34, 2007.

[7] ZENG Xian-tao, REN Zhen-hua, WANG Xing-guo. Experimental investigations on reducing the dust density and the springback rate of shotcrete by using magnetized water. JOURNAL OF CHINA COAL SOCIETY, vol. 39, pp. 705-712, 2014.

[8] PANG Jian-yong, LÜ Pei. Test and application of polypropylene concrete bar shell bolting shotcrete support system in soft rock drift. Rock and Soil Mechanics, vol. 31, pp. 3929-3834, 2010.

[9] GAO Zhi-hua, HE Zhen, ZHAO Xiao, et al. Improvement of Shotcrete's Durability by Ground Granulated Blast-Furnace Slag for Underground Water-sealed Oil Storage in Rock Caverns. Journal of Yangtze River Scientific Research Institute, vol. 31, pp. 97-103, 2014.

[10] YAO Chuan-qin. The Application of Polypropylene Fiber Concrete Spray Layer in Mining Engineering. Journal of Anhui University of Science and Technology(Natural Science), vol. 28, pp. 26-29, 2008.

[11] LIU Xin-rong, ZHU Yun-hua, LI Xiao-hong. Experim-ental research on single-layer tunnel lining of steel fiber shotcrete. Rock and Soil Mechanics, vol. 30, pp. 2319-2323, 2009.

\footnotetext{
Received: May 26, 2015

(C) Qingbiao et al.; Licensee Bentham Open.
}

This is an open access article licensed under the terms of the (https://creativecommons.org/licenses/by/4.0/legalcode), which permits unrestricted, noncommercial use, distribution and reproduction in any medium, provided the work is properly cited. 